\title{
Alienación y Miseria: Tratamiento filosófico desde Marx y \\ Feuerbach $^{*}$
}

\section{Alienation and Misery: Philosophical treatment by Marx and Feuerbach}

\author{
Por: Galizzi Ortega Daiana $\mathrm{G}^{*}$ \\ Universidad Nacional del Nordeste. \\ E-mail: daianagalizzii17@gmail.com
}

Fecha de recepción: 15/03/2021

Fecha de aprobación: 01/04/2021

DOI: http://dx.doi.org/10.30972/ach.065600

\section{Resumen}

El objetivo de este trabajo es problematizar la cuestión de la alienación y exponer sus efectos perjudiciales para la vida del hombre. Para ello, partiremos del concepto de alienación en Feuerbach y nos serviremos de las obras: La esencia de la religión (2005) y La esencia del cristianismo (1995). En estas obras profundizaremos en la alienación del sujeto mediante la religión.

En un segundo momento desarrollaremos los efectos nocivos de la alienación en el hombre según Marx. Las escritos elegidos para esto son: La Ideología alemana (I) (2010), Los manuscritos de 1844 (1972) y por último, El manifiesto del partido comunista (1991). Desde estas obras abordaremos la noción de alienación del sujeto mediante trabajo, su producción y reproducción en todos los ámbitos de la existencia del sujeto. Nuestro interrogante será ¿por qué la alienación es tan nociva para el hombre?

Por último, explicaremos las similitudes y diferencias entre Marx y Feuerbach, exponiendo de qué manera Marx toma el concepto de alienación de su antiguo maestro para adaptarlo y mejorarlo. También nos serviremos de una carta inédita que

\footnotetext{
* El presente trabajo fue realizado en el contexto de Seminario I: Análisis de una obra filosófica.

* Estudiantx de la Licenciatura en Filosofía de la Facultad de Humanidades (UNNE).
} 
Abril 2021.

ISSN 2344-9934

data del año 1844 escrita por Karl Marx y dedicada a Ludwig Feuerbach, encontrada en la obra El humanismo premarxista de Ludwig Feuerbach (1975) de Cabada Castro.

Para finalizar realizaremos una comparación entre discrepancias y similitudes, tanto del concepto de enajenación como de la propuesta de superación en ambos autores.

Palabras claves: Alienación, Marx, Feuerbach, Religión, Trabajo.

\section{Abstract}

The aim of this work is to problematize the question of alienation and expose its detrimental effects on man's life. For this, we will start from the concept of alienation in Feuerbach and we will use the works: The essence of religion (2005) and The essence of Christianity (1995). In these works we will delve into the alienation of the subject through religion.

In a second moment we will develop the harmful effects of alienation on man according to Marx. The writings chosen for this are: The German Ideology (2010), The Manuscripts of 1844 (1972) and finally, The Manifesto of the Communist Party (1991). From these works we will address the notion of alienation of the subject through work, its production and reproduction in all areas of the existence of the subject. Our question will be why is alienation so harmful to man?

Finally, we will explain the similarities and differences between Marx and Feuerbach, explaining how Marx takes the concept of alienation from his former teacher to adapt and improve it. We will also use an unpublished letter dated 1844 written by Karl Marx and dedicated to Ludwig Feuerbach, found in Ludwig Feuerbach's The Pre-Marxist Humanism (1975) by Cabada Castro.

Finally, we will make a comparison between discrepancies and similarities, both of the concept of alienation and of the proposed overcoming in both authors.

Key words: Alienation, Marx, Feuerbach, Religion, Work. 
Cómo citar este artículo:

APA: Galizzi Ortega, D. G. (2021). Alienación y Miseria: Tratamiento filosófico desde Marx y Feuerbach. Acheronta, № 6, 27-49. Recuperado de: (agregar dirección web)

\section{LA ALIENACIÓN EN LA RELIGIÓN SEGÚN FEUERBACH}

Feuerbach, inicia su obra La esencia de la religión (2005) diciendo que el hombre nace en un mundo hostil y generoso. El mundo es generoso cuando la naturaleza le provee alimento, agua, abrigo y morada; a su vez el ser humano es un ser que hereda gratuitamente múltiples cualidades y capacidades para manipular la naturaleza, ejemplo de esto es la tecnología, el arte y primordialmente las ideas. Sin embargo, el ser humano aún así considera que el mundo es hostil, esto se debe a que siente miedo, inseguridad ante la inmensidad del mundo; que en primera instancia lo sienten como peligro en potencia, entonces "Ignoran sus leyes, son incapaces de domeñarlo y sienten ante él su inferioridad e impotencia constitutivas, que enseguida se transforman en miedo y en necesidad de protección" (Feuerbach, 2005, p.11).

A partir de esta sensación de inferioridad y la necesidad constante de protección, creen sumamente indispensable contar con protección de distintas índoles para sobrevivir, de lo contrario perecerán. De esta forma inicia la odisea acerca de la religión del hombre, ya que según el autor: "El sentimiento de dependencia del hombre es el fundamento de la religión" (Feuerbach, 2005, p.21).

Para Feuerbach, el hombre desde sus orígenes experimenta el sentimiento de dependencia, a partir del cual sabe que su existencia como hombre y también su subsistencia no dependen exclusivamente de él, como expone el autor: "Es una necesidad útil al hombre, una necesidad sobre la que se asienta su propia existencia" (Feuerbach, 2005, p.55). El hombre necesitó en un momento primigenio la ayuda de otros entes distintos de él para surgir y llegar a constituirse como tal, y también necesita constantemente de otros entes para asegurar su subsistencia como especie. De esta forma comienza a sentir dependencia o necesidad de ellos. Es por esto que 
Abril 2021.

este sentimiento se da de forma conciente y racional solamente en los hombres, y es el rasgo que lo distingue de los animales; de esta manera comienza a aparecer en el hombre lo que se erige como religión.

Dirá Ludwig que en el desmesurado intento del ser humano por salvarse del naufragio existencial, nace dentro de sí algo mágico; surge el fanatismo por intentar salvarse ante cualquier inconveniente que se le presente, en conclusión lo que surge en el hombre es el deseo, la fe en algo. El autor amplía el concepto de deseo de la siguiente forma:

En definitiva, el deseo de resolver el enigma de la existencia, para cuya satisfacción el ser humano inventa la práctica de la magia, las creencias supersticiosas en lo sobrenatural, la religión en sus múltiples formas, el culto a los antepasados, el animismo, al politeísmo, el monoteísmo. (Feuerbach, 2005, p.12)

De esta forma, Feuerbach concibe a la religión como esencial, además en esta instancia de La esencia de la religión, no diferencia los tipos de religiones sino que las convoca a todas bajo el término del "sentimiento de dependencia", es decir, es religión; todo aquello que se exprese bajo el sentimiento de dependencia o la conciencia del hombre de no poder existir independientemente de un ente distinto de sí y no deberse siquiera su propia existencia a sí mismo.

De esta brecha nace la alienación respecto a la religión, la alienación o enajenación adquiere un carácter negativo y problemático según Feuerbach, ya que el problema surge cuando el hombre no distingue su ser individual y concluye objetivandose un ente divino, independiente de él. El autor afirma que los seres humanos ya no contemplan los cuerpos celestes, el tiempo, entre otros como un ente divino, actualmente el objeto de adoración es Dios. Sin embargo, ¿qué es, quién es Dios para el hombre? El Dios que presenta Feuerbach, es infinito, metafísico, trascendente, único; pero lo que adquiere mayor importancia en esta concepción feuerbachiana, es la denuncia de que el hombre concibe a Dios con características 
humanas, el autor afirma que Dios es el "Yo perfeccionado del hombre"(Feuerbach, 1995, p.18).

En esta concepción humanizada de Dios o culto divino se conjugan la antítesis de los defectos del hombre y sus virtudes potenciadas, por lo que en Dios se hacen posibles todas las limitaciones del hombre. Es por esto que el hombre queda reducido a nada, ya que cuanto más vanagloriado y grande en cualidades es Dios, se produce "La interdependencia y relación inversa entre el hombre y Dios, que al destruir a uno enriquece al otro, y viceversa"(Cabado Castro, 1975, p.55).

La alienación en Feuerbach, aparece como el hombre que no es capaz de afrontar la realidad, que no es capaz de afrontar el mundo en su totalidad y tampoco la vida en su complejidad. Por lo que se generó un paralelismo en el hombre, donde esta dualidad está compuesta por un sujeto que se reconoce como propio (en sí). Mientras que la otra parte del sujeto la reconoce como algo ajeno de sí mismo, por ende funciona como espejo, ya que objetiviza las carencias humanas, haciéndolas posible mediante la objetivación de un (objeto suyo), en este caso ese objeto inventado o producido por el hombre, es decir, Dios.

De esta forma, la enajenación del hombre se produce a partir de la religión, ya que el sujeto no reconoce como propias las cualidades con las que concibe a Dios, que según Feuerbach no es más que un espejo del hombre desconectado de su interior; Cabada Castro (1975) expone: "el hombre tiende a subtantivizar y plasmar su propia esencia fuera de sí mismo, denominando incluso "dios", pero este "dios" no es más que el mismo"(p. 54).

El fundamento de la creencia de Dios se basa en el modo en que este se manifiesta sobre la naturaleza, según la creencia del ser humano, Dios obra mediante la naturaleza. Esto supone que la naturaleza es dominada por un ente distinto de sí. Sin embargo, la raíz de esta creencia errónea nuevamente retorna en el hombre, sentencia Feuerbach (2005): "Y se puede decir sin ningún reparo que mirándolo así, la naturaleza es verdaderamente poseída por un espíritu, pero este espíritu es el del hombre, es su propia fantasía". (p.30) 
Feuerbach, explica este movimiento del razonamiento humano, como un intento de querer explicar todo aquello que no conoce y en este caso precede a su propia existencia. ¿Qué es lo único por encima del hombre y que no puede ser explicado? La naturaleza, que es independiente del ser humano, a su vez es mucho más grande que el ser del hombre y puede seguir existiendo sin él. Pero el ser humano no puede concebir la idea de que la naturaleza sea en sí misma su propio motor y no Dios como ente "sobrenatural", el autor amplía esta idea afirmando:

La creencia de que Dios, presentado como un ser sobrenatural y distinto de la naturaleza, tenga una existencia independiente de la del hombre y de que sea, como dicen los filósofos, un ente objetivo tiene su raíz en el hecho de que originariamente el ente objetivo y que existe aparte del hombre, esto es, el mundo, la naturaleza, es considerado Dios. (Feuerbach, 2005, p.35)

De esta forma, podemos afirmar que debido a la arrogancia y egocentrismo del ser humano, éste no reconocer su incapacidad para conocer todo. Por ello, atribuye todas las cualidades y potencialidades de la naturaleza a Dios, como único ente creador y dominador de la misma.

El argumento que utiliza Feuerbach para desmentir el poderío de Dios sobre la naturaleza, es afirmar que si la causa primera de la naturaleza es un ente sobrenatural, consecuentemente todo lo producido por este debería ser sobrenatural o espiritual (Feuerbach, 2005).

Por otra parte, la inteligencia juega un rol primordial en la idea del hombre acerca de la realidad, ya que "La inteligencia es, ella misma, el "predicado" por excelencia del hombre (...) en cierto sentido, "infinitiza" (al estar abierta a todo) la perfección del hombre"(Cabada Castro, 1975, p.24). En palabras sencillas, la inteligencia o el intelecto humano es el que se relaciona de modo directo con la realidad material, por ende es el encargado de los modos de pensamiento y en consecuencia de la consciencia de sí. El hombre desde los principios de su existencia 
siente terror, miedo, inseguridad por lo externo y llega a considerarlo como un peligro, por lo que genera dependencias que le dan la sensación de cuidado.

En la actualidad, con el crecimiento de la humanidad y la evolución de las religiones, es cierto que se produjo otra forma de miedo, pánico hacia lo externo, lo cual es justificado por una mirada soslayada de la religión como una necesidad de establecer nuevos y más límites para el sujeto, dividiendo el plano terrenal al celestial y mucho peor sometiendo al hombre al culto de Dios.

Por lo tanto, lo que el intelecto humano ve de la realidad es el sometimiento, que en segunda instancia genera pensamientos y una consciencia de sí escindida, ya que el hombre no percibe todo el proceso previo de la enajenación, no encuentra la raíz del problema, ya que ni siquiera se conoce a sí mismo. Es por esto que afirmamos que la conciencia de Dios es autoconciencia del hombre (Feuerbach, 2005). Por ende, el desconocimiento de sí mismo del hombre lo lleva a objetivar un ente externo: Dios.

Los efectos nocivos de la alienación respecto a la religión en Feuerbach se da en un proceso gradual y destructivo para el sujeto, éste se encuentra tan sumido en la miseria que cree que es la existencia se reduce en eso, no llega a vislumbrar una luz en el horizonte de la especie humana, entonces "desea con todas sus fuerzas la liberación de todos los límites y miserias de su propia existencia; Dios no es más que el símbolo de este deseo profundo del hombre" (Cabado Castro, 1975, p.57).

Esto se debe a que el hombre estuvo sometido por miles de años a la religión en sus diversas formas, sin embargo, desde la llegada de religiones como el cristianismo, el sujeto no puede concebirse como un ser activo y parte del mundo en el que habita "Por eso, para librarme de esta vergüenza, de esta intranquilidad, atribuyó los límites de mi individualidad a una cosa inherente a la esencia humana misma" (Feuerbach, 2005, p.13).

Dios representa el intento del ser humano de escapar de la miseria de su existencia la cual no es capaz de afrontar, el Dios que venera el hombre; es el Dios que sufre dirá el autor: "Dios, como Cristo, es el máximo de toda la miseria humana"(Feuerbach, 2005, p.164). 
Sin embargo, el cristianismo ha puesto toda la negatividad en el plano terrenal, haciendo de las cuestiones más necesarias como la procreación algo pecaminoso. Toda cuestión moral tiene un transformó religioso, esto genera que el sujeto no puede ser partícipe en su propio cuerpo y decisiones, ya que de pecar será desterrado del futuro plano celestial. En palabras del autor:

La idea de ser moralmente perfecto, no es de ninguna manera sólo una idea teórica y pacífica, sino que a la vez es práctica, pues incita a la acción y a la imitación y me pone en tensión y contradicción conmigo mismo (...). Y esta discrepancia es en la religión tanto más penosa y tanto más terrible por cuanto opone al hombre su propio ser, como si fuera otro. (Feuerbach, 2005, p.44)

En conclusión, el cristianismo pretende separar lo netamente humano como las pasiones y virtudes por considerarlas dañinas para la fé, que suponen una especie de higiene espiritual donde el hombre ya no es un hombre, por lo tanto siente vergüenza de sí y de la especie. Irónicamente Cioran (2006) plantea “¿Caer en la tentación no significa caer en la vida?" (p.90).

\section{LA ALIENACIÓN EN EL TRABAJO SEGÚN MARX}

El ser humano se diferencia de los animales por múltiples motivos, como por ejemplo; la conciencia, la religión, la racionalidad, el habla, para Marx en cambio, las diferencias entre uno y otro son muy distintas. El autor alemán sostiene que:

Se puede diferenciar a los seres humanos de los animales por la conciencia, por la religión o por lo que se quiera. Ellos mismos comienzan a diferenciarse de los animales en cuanto comienzan a producir sus subsistencias (...). Al producir sus subsistencias, los seres humanos producen indirectamente su vida material misma. (Marx y Engels, 2010, p.36) 
La principal diferencia entre el hombre y el animal radica entonces en la capacidad del hombre de poder producir su vida material, es decir, el hombre es capaz de producir, y realizarse mediante el trabajo. Sin embargo, podemos decir que no solo la especie humana tiene la capacidad de producir los medios de subsistencia, ejemplo de esto son los castores, hormigas, entre otras. Pero la diferencia sigue estando presente, ya que el animal "produce únicamente lo que necesita inmediatamente para sí o para su prole; produce unilateralmente, mientras que el hombre produce universalmente"(Marx, 1972, p.112).

El ser humano puede proyectar sus objetivos a largo plazo, es decir su fuerza productiva puede estar abocada a algo más que las necesidades básicas vitales como lo son la alimentación, la vivienda, la vestimenta, etc. Mediante el trabajo se manifiesta él y su aspecto social, con aspecto social hacemos referencia a que el sujeto no puede permanecer aislado, individual o fuera de la esfera social, por lo que para la especie humana es indispensable establecer relaciones con otros hombres.

Además, también se manifiesta el carácter genérico de la especie, ya que solo de forma social el individuo puede reafirmarse como parte de la especie, es decir como ser genérico. Para que el hombre pueda realizarse como ser genérico, universal y libre debe poder encontrarse en el trabajo, el cual debe ser una actividad libre y consciente en la cual el trabajador produzca y cree un mundo objetivado a partir de la naturaleza y los medios de producción que está le brinda. El autor amplía esta idea de la siguiente forma:

El hombre es un ser genérico. No sólo porque en el plano práctico y teórico hace del género, tanto del suyo propio como del de las demás cosas, su objeto, sino además (...) porque se comporta frente a sí mismo como frente al actual género viviente, porque se comporta frente a sí mismo como frente a un ser universal y, por tanto, libre. (Marx, 1972, p.106) 
Para Marx, el sujeto se realiza sólo mediante el trabajo y lo considera sólo bajo las condiciones de: libertad, creatividad, conciente y como actividad voluntaria. Este sentido del trabajo como realización de la especie humana, comprende al hombre como un sujeto que se sirve de los materiales que le brinda la naturaleza, que produce las condiciones materiales y en consecuencia domina de cierto modo la naturaleza.

En este sentido la especie humana llega a realizarse mediante el trabajo, desarrollando así toda su capacidad productiva, reflexiva, en aras al bienestar de los hombres quedando sujeto a estos los cambios necesarios para su felicidad, ya que es en el trabajo donde el sujeto debería poder cumplirlas.

Sin embargo, cuando en el capitalismo las condiciones para la objetivación de la esencia humana no se respetan, surge lo que Marx denomina alienación o enajenación. Es en el capitalismo donde estos valores son invertidos, quedando las necesidades, los objetivos y la existencia de una parte de los hombres anuladas mediante el trabajo.

A partir del nacimiento del nuevo sistema mundial "capitalista" se ven afectados todos los hombres, por la introducción de múltiples cambios en el orden social y sus respectivas relaciones, como lo son la burguesía y el proletariado, a las que autor los define como:

Por burguesía se comprende a la clase de los capitalistas modernos, propietarios de los medios de producción social, que emplean el trabajo asalariado. Por proletarios se comprende a la clase de los trabajadores asalariados modernos, que, privados de medios de producción propios, se ven obligados a vender su fuerza de trabajo para poder existir. (Marx y Engels, 1991, p.32)

Con el nuevo orden social, se ve afectado de forma directa el trabajo, la producción, pero lo que genera mayor problema es el nuevo modo en que se concibe el producto, ya que se ve escindido del que las produce, es decir, del trabajador. En 
palabras del autor "el objeto que el trabajo produce, el producto, se enfrenta a él como ser extraño, como un poder independiente del productor" (Marx, 1972, p.105).

Anteriormente mencionamos que según Karl Marx, el hombre consigue realizarse solo mediante el trabajo, es por esto que la alienación es la antítesis de dicha realización, en palabras del autor "Esta realización del trabajo aparece en el estadío de la de Economía Política como desrealización del trabajador, la objetivación como pérdida del objeto y servidumbre a él, la apropiación como extrañamiento, como enajenación" (Marx, 1972, pp.105-106).

Entonces, el trabajador es el proletario del sistema capitalista en auge, lo que caracteriza al trabajador son todas las denominaciones contrarias a las necesarias para la realización del hombre descritas por Marx. Por lo tanto, el trabajo del obrero no es creativo, ya que en la mayoría de las veces no es algo con lo que se identifique el sujeto o que represente su ser; por otra lado tampoco es voluntario, ya que es sujeto se ve obligado a vender sus fuerzas de trabajo para solventar sus necesidades, de lo contrario moriría.

En la medida que el sujeto se introduce más y más en el sistema capitalista, más complicaciones se producen en torno a toda su existencia. Otra característica para la realización del hombre era la actividad consciente, sin embargo, es también imposibilitado por parte del capitalismo, ya que respecto a la fuerza del trabajo, el obrero tampoco llega a ser consciente de su actividad, sus metas u objetivos. Como consecuencia se produce la cosificación del trabajo, concepto muy renombrado por Marx; que en definitiva significa que el sujeto vende sus fuerza de trabajo.

Las fuerzas de trabajo son una parte del sistema capitalista que comprende sólo al obrero, donde, volvemos a repetir, su única herramienta es la fuerza de trabajo tanto para solventar a su familia como a sí mismos. Sin embargo, esta fuerza de trabajo es cuantificada por ciertos parámetros impuestos por los burgueses, que en primera y última instancia son los que llevan la delantera. Los burgueses son lo que poseen el capital, los medios de producción y a su vez también poseen mano de obra pesada al menor costo. 
Por otra parte, las relaciones que se establecen en el campo laboral también son ficticias, partiendo de la relación de los burgueses que sólo se relacionan con los proletariados para asegurar aún más sus ganancias, en cambio los obreros se ven necesariamente obligados porque de lo contrario morirían de hambre. A esto se reduce que los burgueses puedan establecer libremente los parámetros con los que se miden la paga a los obreros, las condiciones laborales y estos últimos no puedan hacer más que acatar dichos parámetros.

Todo esto constituye a la alienación mediante el "proceso de producción". En los Manuscritos de 1844, Marx desarrolla este tipo de enajenación, en resumen la alienación parte desde la actividad hacia afuera, desde lo que se produce, hasta las relaciones para con los otros, ya que la enajenación se manifiesta en todo el ser del hombre. En palabras del autor:

El extrañamiento no se muestra solo en el resultado, sino en el acto de producción, dentro de la actividad productiva misma. ¿Cómo podría el trabajador enfrentarse con el producto de su actividad como con algo extraño si en el acto mismo de producción no se hiciese ya ajeno a sí mismo? El producto no es más que el resumen de la actividad, de la producción. Por tanto, si el producto del trabajo es la enajenación, la producción misma ha de ser enajenación activa, la enajenación de la actividad; la actividad de la enajenación. (Marx, 1972, p.108)

La alienación implica volcar fuera de sí lo que es propio y netamente del ser humano, esto que se vuelca fuera de sí se pierde volviéndose completamente extraño. Para Marx lo propio del ser humano y su característica más importante es el trabajo. El hombre no se autopercibe como factor activo en la construcción y captación del mundo, sino se percibe como un factor pasivo, donde realmente cree que le toca acatar el orden impuesto, y hacer de su existencia lo que este mundo le depare, dejando a un sujeto miserable e incapaz de afrontar o de reconocer lo más propio de sí. 
La alienación en Marx se da por medio del hombre en el trabajo, es decir el trabajo (objeto) es irreconocible como algo propio, por ende le es extraño y hostil. En el trabajo, el hombre debería representarse a sí mismo, proyectarse a sí mismo en el objeto producido, en el trabajo el sujeto no se afirma, se niega. En consecuencia, si el sujeto no se afirma en el trabajo, no puede autopercibirse como parte de la especie, es decir no puede proyectar a todo el género humano en su actividad. El sujeto alienado es un ser miserable, infeliz e incapaz que no logra autopercibirse como generador del mundo en el que se encuentra. En palabras del autor:

La enajenación del trabajador en su producto significa no solamente que su trabajo se convierte en un objeto, sino que existe fuera de él, independiente, extraño, que se convierte en un poder independiente frente a él; que la vida que le ha prestado al objeto se le enfrenta como cosa extraña y hostil. (Marx, 1972, p.106)

La alienación también carcome la esencia, el ser del hombre, es por esto que afirmamos que la esencia genérica del hombre también resulta ser alienada y es donde más logra expandirse los efectos de este problema. Comenzamos esta sección hablando acerca de las diferencias entre el hombre y el animal, ahora tenemos un nuevo concepto de hombre el cual es producto de la alienación sufrida, actualmente encontramos al hombre mucho más asemejado al animal, antes decíamos que la diferencia era la capacidad de producir reflexivamente su vida, es decir poder trabajar. Esta semejanza entre el hombre y el animal nace a partir del problema de la alienación y sus efectos nocivos para la vida, donde el hombre no ve al trabajo como una forma de realización sino como un medio, un medio para cumplir necesidades básicas para la subsistencia, es así como el sujeto ve al trabajo como una obligación donde no disfruta en lo absoluto de su actividad, donde "la propia acción del ser humano se le convierte en un poder ajeno, que se halla enfrente, que se le subyuga, en vez de que él la domine" (Marx y Engels, 2010, p.66). 
Por lo tanto, lo que debería ser la forma de realización del hombre se convierte en su enemigo, el hombre sólo consigue sentirse libre en las actividades animales, es decir, comer, beber, engendrar, todo aquello que hace a un animal. Sin embargo, realizar estas actividades también son propias del hombre, pero la diferencia se establece cuando el hombre las separa del ámbito restante de la actividad humana para hacer de ellas su único fín (Marx, 1972).

En última instancia, la alienación también afecta la relación con los otros, cuando decimos que el hombre ya no se realiza genéricamente significa que no se reconoce a sí mismo, así como tampoco reconoce su trabajo, tampoco reconoce el trabajo de los otros, por ende no reconoce a sus pares. Marx lo llama enajenación del hombre respecto al hombre, esto implica que:

Lo que es válido respecto de la relación del hombre con su trabajo, con el producto de su trabajo y consigo mismo, vale también para la relación del hombre con el otro y con el trabajo y el producto del trabajo del otro. (Marx, 1972, p.113)

En conclusión, la alienación en Marx nos presenta los efectos nocivos para la existencia, ya que los beneficiarios del sistema capitalista son solo los burgueses, mientras que el proletariado en su totalidad se ve afectado de forma muy negativa. La existencia del proletario se reduce a cumplir necesidades de subsistencia como único fin, sin aspiraciones de progresos o de cambios si permanecen las mismas condiciones en las que se encuentran. Por estos motivos afirmamos que la alienación es el mayor problema para la existencia del hombre. Marx en Los Manuscritos de 1844 (1972) define de una forma completa lo que representa la alienación del hombre respecto al trabajo:

¿En qué consiste, entonces, la enajenación del trabajo?. Primeramente en que el trabajo es externo al trabajador, es decir, no pertenece a su ser; en que en su trabajo, 
el trabajador no se afirma, sino que se niega; no se siente feliz, sino desgraciado; no desarrolla una libre energía física y espiritual, sino que mortifica su cuerpo y arruina su espíritu. Por eso el trabajador sólo se siente en sí fuera del trabajo, y en el trabajo fuera de sí. Está en lo suyo cuando no trabaja y cuando trabaja no está en lo suyo. Su trabajo no es, así, voluntario, sino forzado, trabajo forzado. Por eso no es la satisfacción de una necesidad, sino solamente un medio para satisfacer las necesidades fuera del trabajo. Su carácter extraño se evidencia claramente en el hecho de que tan pronto como no existe una coacción física o de cualquier otro tipo se huye del trabajo como de la peste (Marx, 1972, pp.108-109).

\section{PROPUESTAS DE LUDWIG FEUERBACH}

La propuesta de Ludwig consiste en liberar al hombre de la alienación que produce la religión, ya que considera más que necesario poder devolver al hombre a la tierra El hombre para poder liberarse debe ser capaz de poder unir las partes escindidas en él, reconociendo que divinizaba las cualidades netamente humanas; Castro afirma:

Feuerbach insiste únicamente en la unidad (que debe ser condición previa de la diferencia y su conocimiento), sacrificando las diferencias en aras de la primera, con el objeto de unir de este modo al hombre consigo mismo y liberarlo así de toda alienación. (Cabada Castro, 1975, p.54)

Luego de esto, el sujeto será capaz de poder reconocer su propio potencial y volver plenamente al mundo terrenal, uniendo finalmente al hombre con el hombre que en última instancia es el objetivo primordial en Feuerbach. El hombre al reconocer que la consciencia de Dios no es más que la conciencia del hombre, se encontraría en posición de poder superar la alienación como enfermedad que produjo la religión.

Feuerbach pretende lograr este objetivo reemplazando el culto/adoración de Dios al hombre, ya que Dios simplemente es la esencia del hombre objetivada, por lo 
Abril 2021.

que pretende que luego del autoconocimiento y liberación de la alienación puedan depositar conscientemente el amor a Dios al hombre. Cabada Castro (1975) sintetiza la propuesta de Ludwig afirmando "el reconocimiento de la conciencia de Dios no es sino la consciencia de la especie; que el hombre puede y debe superar los límites de su individualidad y personalidad, pero no las leyes, las propiedad esenciales de su especie" (p.30).

Esto se debe a que como hacíamos mención al principio del trabajo, la religión es la esencia del hombre, en consecuencia solo puede cambiarse el depósito donde el ser humano coloca toda su fe y amor. Para Ludwig, el amor es la forma de redimir el sufrimiento que genera la alienación por lo que argumenta que mediante el amor el hombre es capaz de abandonar el culto de Dios para poder dar este amor genuino a un ser idéntico así, el autor amplía esta idea afirmando:

Es el amor, porque no Dios como Dios nos ha redimido, sino el amor, que está por encima de la diferencia entre la personalidad divina y la humana. Así como Dios ha renunciado a sí mismo por amor, así también nosotros por amor deberíamos renunciar a Dios (Feuerbach, 1995, p.150).

De este modo, Feuerbach considera que es momento de llevar las riendas de la religión y poner a disposición de la especie la fe y que esta pueda ser beneficiosa para el hombre en la tierra, quedando de este modo Feuerbach como el padre o fundador del humanismo materialista.

\section{PROPUESTA DE KARL MARX}

La propuesta de Marx para que deje de producirse más alienación en el trabajo, consiste en derribar el capitalismo y con él sus formas de propiedad privada y clases mediante una revolución del proletariado. En La ideología alemana se expresa cómo deben darse las condiciones para que esto suceda: 
Esta alienación (...) sólo puede ser abolida bajo dos condiciones prácticas, naturalmente. Para que se convierta en un poder "intolerable", es decir, un poder con el cual se haga una revolución, es necesario que haya procreado a la masa de la humanidad como "sin propiedad" (...). Y, por otro parte, este desarrollo de las fuerzas productivas. (Marx, 2010, p.70)

El proyecto político que según Marx es capaz de terminar con el capitalismo es el comunismo, ya que el comunismo tiene como objetivo la unión universal de los hombres bajo una comunidad donde no existan las clases ni la propiedad privada. Marx explica que este proyecto comunista sólo es posible si se desarrolla colectivamente con los pueblos dominantes a la vez, es decir simultáneamente. Marx (2010) concibe que "para el materialista práctico, es decir, para el comunista, se trata de revolucionar el mundo existente, de abordar prácticamente y cambiar las cosas encontradas" (p.88).

Marx afirma que el comunismo es la solución a la alienación porque toma la base real del problema, y desde allí pretende cambiar la realidad existente con la unión de los obreros. Creando nuevos tipos de relaciones para suplantar las anteriores que sometían a los hombres a un trabajo que destruía, tanto materialmente como psicológicamente sus vidas. El autor define al movimiento revolucionario comunista como:

Dirigida contra el modo de actividad que hubo hasta ahora, elimina el trabajo y suprime la dominación de todas las clases junto con las clases mismas, porque es causada por la clase que en la sociedad ya no es considerada como clase. (Marx, 2010, pp.158-159) 
En conclusión, la propuesta de Marx de un Comunismo que libere a las masas es planteado bajo los términos revolucionarios, en el Prólogo de Crítica de la Economía Política (2008) Marx reafirma que: "En la consideración de tales revoluciones (...) los seres humanos se vuelven conscientes de este conflicto y lo resuelven luchando". (p.194)

\section{ACUERDOS Y DISCREPANCIAS ENTRE FEUERBACH Y MARX}

El nexo entre Feuerbach y Marx puede decirse que inició con el proceso de superación de Hegel, sin embargo ambos pensadores alemanas pudieron relacionarse en el periodo de vejez de Feuerbach, donde Marx decidió contactarse con Ludwig. Nuestro interés radica en exponer las influencias feuerbachianas en el posterior desarrollo del pensamiento marxista. Por ello retomamos una carta escrita por Karl Marx para Feuerbach, donde le expresa su profunda admiración:

Me es grato aprovechar la ocasión para expresarle la alta estimación y --si me permite la palabra-- el amor que siento por usted. Su Filosofía de futuro y su Esencia de la fe son, desde luego, a pesar de su volumen reducido, obras de mayor peso que toda la literatura alemana actual junta. En estas obras ha dado usted -no sé si deliberadamente- una fundamentación filosófica al socialismo, y los comunistas han interpretado así estos trabajos desde el primer momento. El concebir la unidad del hombre con el hombre, basada en las diferencias reales entre ellos, y el bajar el concepto del género humano del cielo de la abstracción para situarlo en la tierra real, ¿qué es todo eso más que el concepto de la sociedad? (...). Los artesanos alemanes que trabajan aquí, es decir, los comunistas, varios cientos de ellos, han escuchado este verano dos veces a la semana conferencias sobre su Esencia del cristianismo, dadas por sus instructores secretos y se han mostrado notablemente sensibles a estas enseñanzas. (Cabado Castro, 1975, p.57) 
La admiración de Marx a Feuerbach siempre fue de público conocimiento, sin embargo adquirió más relevancia la crítica de Marx a Feuerbach con su Ad Feuerbach, ya que Marx en el desarrollo de su pensamiento concibió ideas distintas a las de Ludwig, esto no implica que este último no haya sido de relevancia fundamental dentro del sistema de Karl Marx. Incluso uno de sus más grandes nexos es el concepto de alienación que propiamente fue expuesto por Feuerbach mucho antes. La idea de alienación en Marx coincide con la de Feuerbach en la medida en que la alienación adquiere un papel negativo en el hombre, además de que en el proceso de alienación el ser humano objetiviza algo de sí al exterior, es decir, hacen un objeto algo de sí; en Marx esto se da en el trabajo, en el objeto del trabajo, mientras que en Feuerbach se da en un Dios objetivado por el sentimiento religioso.

El tratado que le dan tanto Feuerbach y Marx al concepto de alienación es concordante y similar, llegando a diferenciarse sólo por el aspecto donde plasmaron sus análisis:

\footnotetext{
$<<$ Cuanto más se agota el trabajador en su trabajo, tanto más poderoso se hace el mundo ajeno y objetivo se crea frente a sí mismo; tanto más pobre se hace el mismo, su mundo interior; tanto menos se pertenece a sí mismo. Lo mismo pasa en la religión. Cuánto más se entrega el hombre a Dios, tanto menos se posee él a sí mismo >. (Cabado Castro, 1975, p.170)
}

Las discrepancias entre los autores se hace evidente con sus respectivas propuestas, recordemos que Marx propone como solución a la alienación del hombre en el trabajo, una revolución de la clase proletaria, sembrando así un nuevo sistema: el Comunismo; que se propone como objetivo: destruir el orden anterior con el la diferencia de clases y así también la alienación de los hombres. Sin embargo, Feuerbach se opone a esta idea del Comunismo como solución de los problemas de la sociedad capitalista y respectivamente de la alienación, Cabada Castro (1975) explica dicha oposición: 
En una carta de Feuerbach a Frederich Kapp, de 15 de octubre de 1844, comunica Feuerbach a Kapp sus primeras impresiones sobre el futuro del movimiento comunista: $<<$ Verdaderamente pronto-pronto en el sentido de la humanidad, no de los individuos-tomaran las cosas otro aspecto; los que están arriba se pondrán abajo, los que estan abajo, arriba; los que ahora domina, servirán, y los que ahora sirven, dominaran. Este será el fin del comunismo, no lo que él pretende>>.(p.52)

El argumento de Feuerbach consiste en afirmar que el comunismo no prevé que dicha revolución no tendrá otro fin que invertir el sistema capitalista, sin poder destruirlo por completo y poniendo a otras personas en el rol de proletarios y burgueses. El autor está de acuerdo con disolver las bases del capitalismo y seguir adelante con el proyecto materialista pero no concuerda en la solución que Marx cree posible, Feuerbach (como se citó en Cabada Castro, 1975) afirma: <<El materialismo, es para mi, el cimiento sobre el que descansa del edificio del ser y del saber del hombre (...) Retrospectivamente estoy totalmente de acuerdo con los materialistas, pero no lo estoy mirando hacia adelante.

Por otra parte, la propuesta de Feuerbach consiste en la superación de la alienación mediante el amor y la fe del hombre con el hombre, superando así todo tipo de paralelismo en el sujeto e instaurando las bases del humanismo, sin embargo Marx y Engels (2010) afirman que:

Feuerbach disuelve la esencia religiosa en esencia humana. Pero la esencia no es (...) abstraer del curso de la historia y a fijar en sí en ánimo [Gemüt] religioso, y a presuponer un abstracto -aislado- individuo humano(...) por eso, la esencia sólo puede ser concebida "género" [Gattung], como universalidad interna, muda, que une naturalmente a los muchos individuos. (p.17) 
La crítica de Marx a Feuerbach consiste en afirmar que el pasaje que hace Feuerbach de la esencia religiosa a la esencia humana es idealista, ya que esto supone un tipo ideal de hombre abstraído del curso de la historia como así también de las condiciones materiales y sociales, por lo que la única forma de suponer que la esencia del hombre universal es religiosa es desconocer las condiciones materiales y sociales de la existencia de los sujetos. El humanismo que Feuerbach propone es a los ojos de Marx insuficiente para cambiar los modos de existencia del hombre, acusándolo de haberse quedado en un plano que en parte sigue siendo idealista.

\section{CONCLUSIÓN}

El objetivo del trabajo era exponer un análisis detallado del concepto de alienación tanto en Ludwig Feuerbach como en Karl Marx, además de problematizar dicho concepto exponiendo como se desarrolla un tipo de existencia nociva para los sujetos sometidos a ella.

En el capítulo uno, expusimos el concepto de alienación de Feuerbach, haciendo un recorrido desde los inicios de la humanidad con el concepto del sentimiento de dependencia, cómo se genera y cómo influencia posteriormente en la enajenación. Además cumplimos con el objetivo de la interrogante sobre los efectos nocivos que expone Ludwig respecto a la alienación, es decir, la pérdida y el paralelismo en el sujeto, la inseguridad, el miedo y el desconocimiento sobre sí mismo, produciendo una vida miserable y vacía.

En el capítulo dos, expusimos el concepto de alienación de Marx, la manera en que el autor entiende a la alienación como objetivación del hombre en el trabajo, tanto en su producto, como en el proceso, así también para consigo mismo y para con otros. Cumpliendo también con el objetivo de desarrollar los efectos nocivos de la alienación como por ejemplo, la desvalorización del obrero, las malas condiciones de trabajo, la desrealización de la esencia genérica del hombre, es decir mediante su ser social y en el trabajo. 
En el capítulo tres, presentamos la propuesta de Feuerbach respecto a la enajenación en la religión y cómo para el autor la solución para esta problemática era un proyecto humanista; que tenía como base el amor del hombre con el hombre, teniendo como nuevo objeto religioso al hombre mismo.

En el capítulo cuarto, al igual que en el capítulo anterior, expusimos la propuesta de Marx respecto a la alienación en el trabajo. Como solución el autor suponía que el comunismo era el proyecto político capaz de hacer desaparecer el sistema capitalista, afirmando que con la caída del capitalismo desaparecerían las malas condiciones laborales, como así también las respectivas clases sociales que sometían a los proletarios, es decir a los obreros.

En el quinto capítulo expusimos las similitudes y diferencias entre las distintas concepciones de alienación en ambos autores, además nos servirnos de cartas que enriquecieron el nacimiento del concepto de alienación en Marx, superando de cierto modo a su maestro Feuerbach y así también, expusimos otra carta escrita por Feuerbach declarando su postura discordante con el proyecto del comunismo.

Por otra parte, el análisis del concepto de alienación en Feuerbach y Marx, dió como resultado un tratamiento de dicho concepto similar en términos estructurales en ambos autores, siendo la diferencia el lugar u objeto donde vieron plasmado dicho concepto y respectivamente sus propuestas también son discordantes, ya que la propuesta humanista de Feuerbach termina siendo poco práctica o no concluye con los problemas materiales y sociales de la humanidad. Mientras que para Feuerbach la propuesta de Marx es ampliamente ambiciosa, ya que pretende incentivar a una revolución y posteriormente al proyecto Comunista, teniendo como objetivo el fin de las bases de la desigualdad social. Lo que para Feuerbach Marx no ve es que el comunismo terminaría instaurando un orden social en donde los antiguos proletarios se convertirán en burgueses que someterán a los antiguos burgueses. Esto sería solo invertir los roles de las clases y no un verdadero cambio en las condiciones materiales de producción y existencia. 
Dicho esto, teniendo en cuenta los objetivos y el posterior desarrollo del presente trabajo podemos afirmar que pudimos cumplir con los objetivos previstos.

\section{$\underline{\text { Referencias bibliográficas }}$}

Cabada Castro, M. (1975). El humanismo premarxista de Ludwig Feuerbach. (J. Garrigós, Trad.).Madrid: La Editorial Católica.

Cioran, E. (2006). El ocaso del pensamiento. Bs As: Tusquets Editores.

Feuerbach, L. (2005). La esencia de la religión. (T. Cuadrado, Trad.). Madrid: Páginas de Espuma.

Feuerbach, L. (1995). La esencia del cristianismo. (J. Iglesias, Trad.). Madrid: Trotta.

Marx, K. (2008). Contribución a la crítica de la economía política. (J. Tula, Trad.). Madrid: Siglo veintiuno editores.

Marx, K. (2010). La ideología alemana (I) y otros escritos filosóficos. (J. Vergara, Trad.).Bs As: Editorial Losada.

Marx, K y Engels, F. (1991). Manifiesto del Partido Comunista. Beijing: Ediciones en Lenguas Extranjeras.

Marx, Karl. (1972). Manuscritos de 1844. ( A. García Barceló, Trad.). Bs As: Estudio. 